\title{
The Artistic Characteristics of Nanyang Painting Stone
}

\author{
Hong Zhang \\ Art Design Department \\ Jiyuan Vocational and Technical College \\ Jiyuan, China 459000
}

\begin{abstract}
Painting stone, a kind of architectural material, is artistic language of sculpture. Nanyang painting stone of Han Dynasty boasts various types of material, multiple patterns of manifestation, rich artistic language, mature carving technique, sparse and clear composition, simple and honest lines, distant artistic conception and distinctive visual tension. It is the crystallization of Han culture and an important part of Chinese traditional folk fine arts with great aesthetic research value. Based on development history of Han Dynasty and research on background of prosperous Nanyang painting stone, the paper conducts a complete description of artistic characteristics and unique charm of Nanyang painting stone from five aspects: content, composition, lines, carving and image, laying the foundation for in-depth research on Nanyang painting stone of Han Dynasty in later periods.
\end{abstract}

Keywords-painting stone; Han Dynasty; Nanyang; artistic characteristics

\section{INTRODUCTION}

History never stops moving forward. The rich and profound historical culture of the Chinese nation creates diversified patterns of manifestation of art in different periods. Strict feudal hierarchy in Xia-Shang-Zhou Period brings about stable and solemn artistic expression with symmetry specification. Development of paint technology in Qin Dynasty opens up the bold and unconstrained art of China's wooden furniture. Han culture with Huaxia culture as its core upholds govern by doing nothing that goes against nature and Confucianist, and experiences all flowers blooming together, with Han art experiencing inheritance and development from the pre-Qin period, boasting broad field of vision, great strength of arms, vigor, positivity, elegance and unrestrainedness.

\section{GENERAL DEVELOPMENT OF NANYANG PAINTING STONE}

Painting stone is a kind of architectural component carved and painted on funeral etiquette architecture, like cemetery and coffin chamber, a kind of sacrifice art in essence. The stone carving artwork takes stone as paper and knife as brush, being the treasure of Chinese traditional cultural inheritance. Painting stone of Han Dynasty is extensive and profound, rooted in the magnificent historical stage of Han Dynasty. It absorbs artistic essence of multiple dynasties, describes complicated and confusing things in the world and creates soul-stirring artistic conception. As the concentrated reflection of Han art, painting stone art is the perfect combination of pottery figurine art, stone carving art and calligraphy art of Han Dynasty. Boasting accurate and meticulous extract of sacrifice scene, theme longing for the future, and carving lines and composition form with distinctive personality, Han painting stone is the model of perfect combination of classical realism and romanticism [1].

Nanyang, called Wan in ancient times, is located in southwest of Henan with Funiu Mountain to its north, Han River to its south. It is the headstream of $\mathrm{Chu}$ and Han cultures, one of the five major capitals in the Western Han Dynasty, the place where Liu Xiu as Eastern Han Dynasty emperor lives and rises to power and position. In the period of two Han dynasties, Nanyang is the vital communication line between south and north with rich natural resources and developed economy, becoming a large distributing centre of agricultural trade. Good social environment boosts celebrities coming forth, as bright as stars. As the home to the emperor, Nanyang is the birth place of many royal aristocrats and very wealthy merchants of near relation. Elaborate funeral is very popular with feudal ruling class of Han Dynasty, seeking morality in elaborate funeral. Therefore, people from every class, especially aristocratic stratum, compare with the higher and have huge investment in building tombs. In addition, Nanyang Basin has rich stone resource. Multiple factors breed Nanyang painting stone of Han Dynasty.

Han Dynasty is the first golden development period in the history of China. The governor adopts the policy of reducing the burden of taxation and cost and loosening the control over common people, thus agriculture develops rapidly, handicraft industry develops, population size becomes large, commerce begins its initial development and the whole society boasts a high degree of education, creating the great artistic expression of Han painting stone. Nanyang-centered southwestern Henan and north Hubei are among China's five largest painting stone distribution areas[2], among which Nanyang Han painting stone boasts extremely distinctive personality characteristics, listed as the origin of China's painting stone and the purest native art in art circles. Nanyang Han painting stone originates in late Western Han and experiences a period of great prosperity in earlier and middle Eastern Han with rich content, abundant themes, large number and great momentum, 
boasting concise language and variable forms. Carving technique is highly summarized in pursuit of being alike in spirit with liveliness and primitive simplicity. Unadorned beauty is shown in combination of carving, wood block, patterning and architecture art with strong rhythm sensation and plain and full composition.

\section{ARTISTIC CHARACTERISTICS OF PAINTING STONE}

\section{A. Beauty in Content}

In Han Dynasty, prosperous economy and development of social culture provide an open and free environment for development of Nanyang painting stone, which has a wide range of theme, rich contents and diversified themes. In terms of currently unearthed painting stones, there are two major types of themes:

Real life type: It aims to reflect the real life status of different classes under the background of social and economic development in Han Dynasty. As to life scenes, there is farming, raising livestock, harvesting, cereal, wrangler, riding and shooting, hunting, going out and constructing. As to scenes of entertainment, there are banquets, dance music, opera and party. As to scenes of competition, there is ancient wrestling and striking of warrior. It is re-production and memory of people's real life before death from different classes. There is a large number of painting stone depicting scenes of nobility enjoying the life and painting stone with animal images.

Myth and astronomy type: It aims to reflect people's inheritance from tales of legendia, awe and veneration to immortal ancestors, hope for auspicious birds and beasts, and exploration on astrology and astronomy. There are depiction of mythological figure and generals and ministers, like Fu Hsi and Nuwa, East Duke and Western Queen, the beast with nine human-faced heads, dragon and phoenix, rosefinch and Xuanwu, auspicious sign and becoming immortal, generals and ministers, dutiful son and paragon of chastity. There are also descriptions of historic stories, like feast at Hong Gate, two peaches killing three warriors. As to re-production of astronomy and astrology, there are Altair and Vega, white tiger and black dragon, toad and moon rabbit, and threelegged crow solar disk. Depiction of astronomy and astrology is the most outstanding and most unique content of Nanyang Han painting stone, directly reflecting Han people's research on and achievements in astronomy[3].

\section{B. Beauty in Composition}

Nanyang painting stone pays no attention to figure-ground relation or virtual-real relation emphasized in later art and mainly adopts full composition with no blank in the picture. There are mainly several kinds of composition:

Graphic composition: It boasts complete complanate expression without any perspective change, virtual-real expression or decorative pattern in the blank and with sparse and wide layout, frequently used by Nanyang painting stone in the earlier period. At the beginning development period of painting stone, there are few contents to perform and image is single with natural and pure complanate composition and complete picture. However, the image is too single, lacking changes, decorations and a full feeling. In later period, when reproducing grand and complicated scenes, Nanyang painting stone mostly adopts this kind of composition, with thematic images all over the picture, grand and magnificent.

Three-dimensional composition: It is developed on the basis of complanate composition with partial appearance of perspective relation of foreshortening effects. But there is no vanishing point. Cavalier perspective is adopted, going beyond complete imitation of original images with aesthetic treatment like transformation and exaggeration of image. Observing little from big, from near to far, and rear not to be blocked by the front are adopted. The blank is filled by decorative patterns in proper quantity. This kind of composition is usually adopted in depicting astronomy and astrology. In prosperous period of Nanyang painting stone, according to requirements of painting expression, complanate composition and three-dimensional composition are combined and used alternatively to make the picture full and rich. For example, evident change in density, difference in size and location moving are adopted in arrangement of the same image. When depicting a grand scene, first complanate composition is used to control the overall situation, and then perspective rule of three-dimensional composition is used to enrich the image in every relatively isolated small picture, expanding in-depth expression of the picture.

Split three-dimensional composition: It is similar to the composition of design pattern. Skeleton lines arranged in a certain law are used to split the space in the picture and images are re-set in each space to depict the content. For example, quadrilateral continuity is used in composition with proper pattern to decorate tomb top. This kind of composition has narrow application.

\section{Beauty in Lines}

Line is one of the most basic elements in any kind of art. As a kind of carving art, Nanyang painting stone boasts typical, distinctive and special carving lines, which mainly fall into two types:

Outline line: It refers to lines determining boundary of the picture. Nanyang painting stone mainly uses long outline lines, which are smooth, natural, fluent, concise, generalized and completed at one stretch. Apart from regular modeling using straight lines, like tools and vessels, other modeling, like figure and animal images, uses curves and turning in curved surface with natural transition, diversified changes, strong dynamic sense, curve charm and great visual tension.

Internal line: It is used to depict theme images and decorative pattern in works. Different from external outline lines, internal lines are not even, mainly using expression forms like straight, short, thin, broken, crude, obscure, plain and clumsy. Thin lines are used and the difference between heights of figure and ground is fully used, highlighting governing status of outline lines, enlarging implicit beauty in internal lines and forming the whole picture's artistic style of combination of lines, full of change. To some extent, the fact that internal lines are short and thin is greatly related to the 
feature that it is not easy for painting stone material to achieve meticulous depiction.

\section{Beauty in Carving}

Nanyang painting stone art is a kind of special art form, which is different from traditional painting art. It uses high or low flow of lines and concise expressive language to create works with texture, depicting all things on earth and creating strong visual effects. It is close to carving art[4]. Different from traditional circular engravure and embossment, Nanyang painting stone is the collision of metal and stone with a beauty sense of stroke of an axe and a knife, showing the expansion of Han art and romantic Chu culture. Nanyang painting stone carving technique falls into several types:

Complanate negative line carving: It is an ordinary and common seen carving technique. Namely, negative lines are used to depict the theme in different medium surfaces. Singlet lines are used to depict images with decorative pattern like hard spot, imaginary line and cross breaks to highlight image texture.

Cut-off ground and concave negative line carving: First, decorate horizontal and vertical stripes as the bottom of the whole painting, then carve the theme content into concave and further use negative lines to depict details.

Cut-off ground bas-relief: Namely, the reduction technique. First, chisel stone material into rough plane, then scrape the space outside the theme content into flat ground, horizontal and vertical lined ground or plain ground, use ink lines to draw out the themed image, and use negative lines to depict the outline and make cut-off ground without carving of image details. Ink lines of the outline are invisible or visible, having the effect similar to bas-relief. This kind of carving works boasts sparse composition, concise modeling, plain image, forceful lines, marked picture, unadorned and primitive simplicity, and multiple artistic characteristics of bas-relief, paper cuttings and painting[5].

Bas-relief and negative line carving: This carving technique comes into being on the basis of cut-off ground basrelief technique. Namely, on the basis of last kind of carving technique, negative lines are used to depict details of the theme, creating a real and full image.

As to other carving techniques, there is reduction line carving and concave carving, reduction negative line perspective carving and so on, which are developed based on the above four kinds of basic carving technique. Nanyang painting stone carving follows no set form with multiple variation and co-existence of multiple carving techniques. Carving lines are concise and smooth with great dynamic, completed at one stretch, just like floating clouds and flowing water. Carving layout is sparse and enlightened with prominent theme, opening up the theory of one painting one theme in Chinese painting. What's more, Nanyang painting stone combines realism and romantism with unity of form and spirit, leaving a deep impression on people.

\section{E. Beauty in Image}

Nanyang painting stone's unique and distinctive artistic features are vividly shown by craftsman with a strong sense of beauty in image. As to theme depiction, Nanyang painting stone boasts prominent themes with completeness as a whole. One painting has one theme with neat, orderly, reasonable and clear depiction. Figures are variable with simple outlines and without decorations in details. Artistic treatment like transformation and exaggeration is adopted on the basis of realistic painting. Carving lines boast great dynamic, like floating clouds and flowing water and light dance, showing unique aesthetic characteristics. In terms of modeling, Nanyang painting stone pays great attention to artistic expression of movement and rhythm, like music player's opening arms and dancer's dynamic body post. Quiet or dynamic body language of the theme is shown through image depiction with dynamic and rhythm sensation, endowing the whole painting with a beauty sense in image. Figures are mainly depicted from the side, making it easy to show characteristics of their five sense organs. Nanyang painting stone adopts simultaneous appearance of myth and reality, deity and human, and human and beast, creating the artistic conception of man being an integral part of nature. Affected by Chu culture, Nanyang painting stone boasts distinctive characteristics of romantism. The artistic conception of man being an integral part of nature is fully created. Abundant themes of celestial being and mythical creatures show Chu cultural style. As to decorative pattern, the mostly seen decorative clouding is arc-shaped in the middle and sharp in ending. At the same time of decorating the painting, clouding intensifies painting style, adjusts visual tension of the painting and unifies the painting. The above artistic treatment in multiple aspects constitutes the unique image beauty of Nanyang painting stone.

\section{CONCLUSION}

Nanyang Han painting stone boasts contents revolving multiple subjects. It is the crystallization of Han culture and the artistic flower of multiple cultures, boasting great research value. It has a wide range of theme, diversified patterns of manifestation, rich and full artistic language, mature carving techniques and simple and honest lines, creating the inclusive spirit of man being an integral part of nature, animate reproduction of life, strong and distinct visual tension, and unique artistic appeal. It is an integral part of traditional Chinese folk fine arts, the important witness of prosperous society in Han Dynasty and crystallization of Chinese laboring people's great wisdom. Research on Nanyang Han painting stone should not be limited to conventional artistic expression. It should take a broad view on historical development of Han Dynasty and integrate into the real and ancient days of Han Dynasty to explore the unique and vivid life of Nanyang Han painting stone, making traditional Chinese culture yield unusually brilliant results in the trend of the times. 


\section{REFERENCES}

[1] Cui Xiulian. Profound and Magnificent Nanyang Han Painting Stone[J]. Zhongzhou Today and Yesterday, June 2004.

[2] Xin Lixiang. Comprehensive Research on Han Painting Stone[M]. Cultural Relics Publishing House, the First Version, August 2008.

[3] Yang Xufei. Han and Chu Styles in Ancient Stones --Analysis on Modeling Language of Nanyang Painting Stone[D]. Henan: Henan University, 2004.

[4] Li Zehou, Liu Gangji. History of Chinese Aesthetics[M]. Anhui Literature and Art Publishing House, the First Version, August 1999.

[5] Wang Nan. Analysis on Artistic Style of Nanyang Han Painting Stone and Seal Cutting[J]. Journal of Anyang Teachers College, March 2005 